\title{
In-Situ Rs and Improvement in Thermal Stability of Nickel Silicides Using Different Interlayer Films
}

\author{
Chi-Ting Wu, ${ }^{1}$ Ying-Lang Wang, ${ }^{2}$ Shih-Chieh Chang ${ }^{2}$ and Wen-Hsi Lee ${ }^{1 *}$ \\ 1. Department of Electrical Engineering, National Cheng Kung University, Tainan 701, Taiwan. \\ 2. Institute of Lighting and Energy Photonics, National Chiao Tung University, Hsinchu 30050, Taiwan
}

\begin{abstract}
Different interlayer films (Mo, Ru, Ta, Ti and $\mathrm{Zn}$ ) were proposed to reduce sheet resistance (Rs) and improve thermal stability for nickel (Ni) silicide formation. It was found that the $\mathrm{Zn}$ and Mo interlayers reduced nickel silicide Rs much more than those by the $\mathrm{Ru}$, Ta and $\mathrm{Ti}$ interlayers at $700{ }^{\circ} \mathrm{C}$. The corrosion rates of the $\mathrm{Mo}, \mathrm{Ru}, \mathrm{Ti}$ and $\mathrm{Zn}$ interlayers were higher than that of NiSi in $\mathrm{H}_{2} \mathrm{SO}_{4}: \mathrm{H}_{2} \mathrm{O}_{2}=4: 1$ at $80^{\circ} \mathrm{C}$. Overall, $\mathrm{Zn}$ and Mo were candidates of interlayers for Ni silicide formation due to lower nickel silicide resistivity, high etching selectivity with $\mathrm{NiSi}$ and better thermal stability.
\end{abstract}

Key words: Interlayer, in-situ Rs, NiSi, silicide.

\section{Introduction}

Metal silicides have been widely used in ultra-large scale integrated (ULSI) circuits to reduce the contact resistance of the source/drain in complementary metal-oxide-semiconductor (CMOS) devices. Currently, the most commonly used silicides are $\mathrm{TiSi}_{2}$, $\mathrm{CoSi}_{2}$ and $\mathrm{NiSi}$. For $\mathrm{TiSi}_{2}$, the transformation from the high resistivity C49 phase to low resistivity C54 phase is nucleation limited [1-3], causing line-width dependence of the sheet resistance for gate-lines narrower than submicrometer dimensions. Therefore, $\mathrm{CoSi}_{2}$ and NiSi have emerged as the most promising candidates to replace the $\mathrm{C} 54-\mathrm{TiSi}_{2}$ phase in self-aligned silicide (salicide) technology.

Although $\mathrm{CoSi}_{2}$ is used without significant disadvantages, its high Si consumption and junction spiking have limited its applications with regard to deep submicrometer devices [4]. Neither $\mathrm{CoSi}_{2}$ nor $\mathrm{NiSi}$ have the line-width dependence effects that are observed in $\mathrm{TiSi}_{2}$ [5]. For sub-100 nm silicide technology, $\mathrm{TiSi}_{2}$ and $\mathrm{CoSi}_{2}$ are expected to be replaced by NiSi [6]. For 65-nm node CMOS

Corresponding author: Wen-His Lee, E-mail: leewen@mail.ncku.edu.tw, Tel: 886-6-2757575, Fax: 886-6-2345482. technology, nickel (Ni) silicide is applied for the lower resistance of the gate electrode and to produce diffused single-silicon layers [7, 8].

$\mathrm{Ni}$ silicide is suitable for ULSI because it requires a nano-scale thin film and has a number of desirable characteristics, such as low thermal stress due to low temperature fabrication and low silicon consumption characteristics [9]. However, NiSi agglomeration reportedly takes place at temperatures as low as $600{ }^{\circ} \mathrm{C}$, while its phase transformation from $\mathrm{NiSi}$ to $\mathrm{NiSi}_{2}$ occurs at temperatures above $700{ }^{\circ} \mathrm{C}[4,10]$, and those degrade the performance of the associated devices and give rise to some reliability issues. Recent research has shown that $\mathrm{NiSi}$ is extremely sensitive to oxygen contamination during silicidation, but this can be suppressed by adding a $\operatorname{TiN}_{\mathrm{x}}$ capping layer [11] Accordingly, considerable work has been carried out with the aim of enhancing the phase transformation temperature, specifically by extending the stable temperature region of conventional NiSi by adding a third element, such as Ir or $\operatorname{Zr}[12,13]$.

In this study, the effects of different interlayers were investigated, such as Mo, Ru, Ta, Ti or $\mathrm{Zn}$, on the electrical and thermal properties of Ni silicides. The $\mathrm{Ni}$ film diffusivity in $\mathrm{Si}$ is faster than interlayers (Mo, Ru, 
Ta, $\mathrm{Ti}$ or $\mathrm{Zn}$ ), therefore, the $\mathrm{Ni}$ atoms could pass through the interlayer to form silicide. Using the interlayer to replace the capping layer $\left(\mathrm{TiN}_{\mathrm{x}}\right)$ would be suitable for next-generation CMOS processes. It is shown that the use of an interlayer effectively improves the electrical characteristics, microstructure properties, thermal stability and phase transformation of the samples.

\section{Experiment}

The substrates were p-type silicon (100) wafers. Following a standard RCA (Radio corporation of America) cleaning process, different 5-nm interlayer films (Mo, $\mathrm{Ru}, \mathrm{Ta}, \mathrm{Ti}$ and $\mathrm{Zn}$ ) were sputtered onto a silicon wafer and a 25-nm Ni film was deposited onto different interlayers, as shown in Fig. 1a. The sheet resistance (Rs) of the interlayer $\mathrm{Ni}$ silicide was measured by an in-situ Rs method, as shown in Fig. 1 b. All samples were annealed at temperatures between $50{ }^{\circ} \mathrm{C}$ to $700{ }^{\circ} \mathrm{C}$ and measured by the in-situ Rs method in an $\mathrm{N}_{2}$ ambient.

After the rapid thermal annealing (RTA) silicidation process, the interlayers (Mo, Ru, Ta, Ti and $\mathrm{Zn}$ ) and unreacted nickel film were selectivity etched and removed by dipping in $\mathrm{H}_{2} \mathrm{SO}_{4}: \mathrm{H}_{2} \mathrm{O}_{2}=4: 1$ and $\mathrm{NH}_{4} \mathrm{OH}: \mathrm{H}_{2} \mathrm{O}_{2}: \mathrm{H}_{2} \mathrm{O}=1: 8: 60$ at $80{ }^{\circ} \mathrm{C}$ and $25{ }^{\circ} \mathrm{C}$, respectively.

The silicide phases that formed were identified using glancing-angle X-ray diffraction (GLXRD). The surface morphology was observed by field-emission scanning electron microscopy (FESEM). The electrochemical experiments were performed using an AutoLab PGSTA302N potentiostat/galvanostat with the open-circuit potential (OCP) in the measure-only mode. A conventional three-electrode cell setup with a Pt sheet as the counter electrode and silver/silver chloride $(\mathrm{Ag} / \mathrm{AgCl})(3 \mathrm{M} \quad \mathrm{KCl})$ as the reference electrode was employed.

\section{Results and Discussion}

Fig. 2 shows the in-situ Rs of the silicide layers formed on different metal interlayers with annealing temperatures from $50-700{ }^{\circ} \mathrm{C}$. The silicide of the $\mathrm{Ni} / \mathrm{Si}$ structure without a metal interlayer had Rs of less than $60 \mathrm{ohmic} / \mathrm{sq}$ at temperatures from $50-700{ }^{\circ} \mathrm{C}$. There was a sudden drop in Rs in the $300-400{ }^{\circ} \mathrm{C}$ annealing temperature range that was ascribed to the phase transformation from $\mathrm{Ni}$-rich silicides to $\mathrm{NiSi}$ because NiSi has the lowest resistivity of the examined materials. When metal interlayers were inserted, the $\mathrm{Rs}$ of $\mathrm{Ni}$ silicide was lower at annealing temperatures below $400{ }^{\circ} \mathrm{C}$. In contrast the $\mathrm{Ni} / \mathrm{Si}$ without any interlayer

(a)

\begin{tabular}{|c|c|c|c|}
\hline Ni film & Silicidation & Metal interlayer & Remove interlayer \\
\hline $\begin{array}{l}\text { NIIIIII } \\
\text { Metal interlayer }\end{array}$ & & Nickel-Silicides & Nickel-Silicides \\
\hline Si Sub. & & Si Sub. & Si Sub. \\
\hline
\end{tabular}

(b)

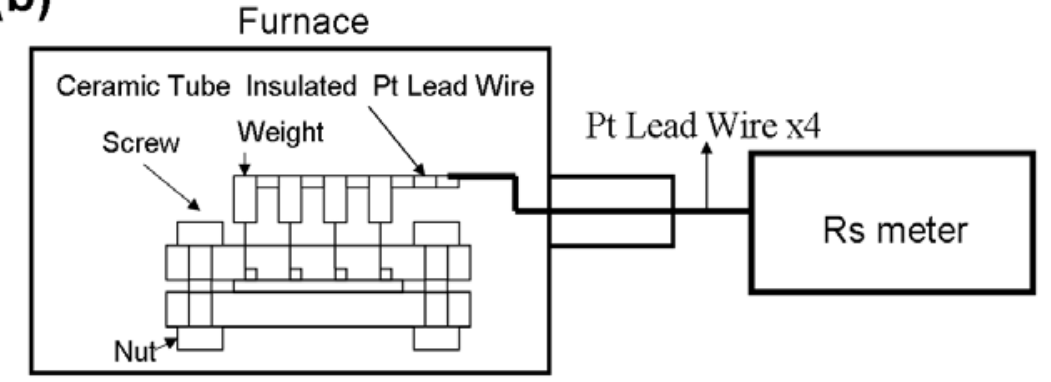

Fig. 1 Illustration of experimental procedure: (a) sample process and (b) In-situ Rs method. 


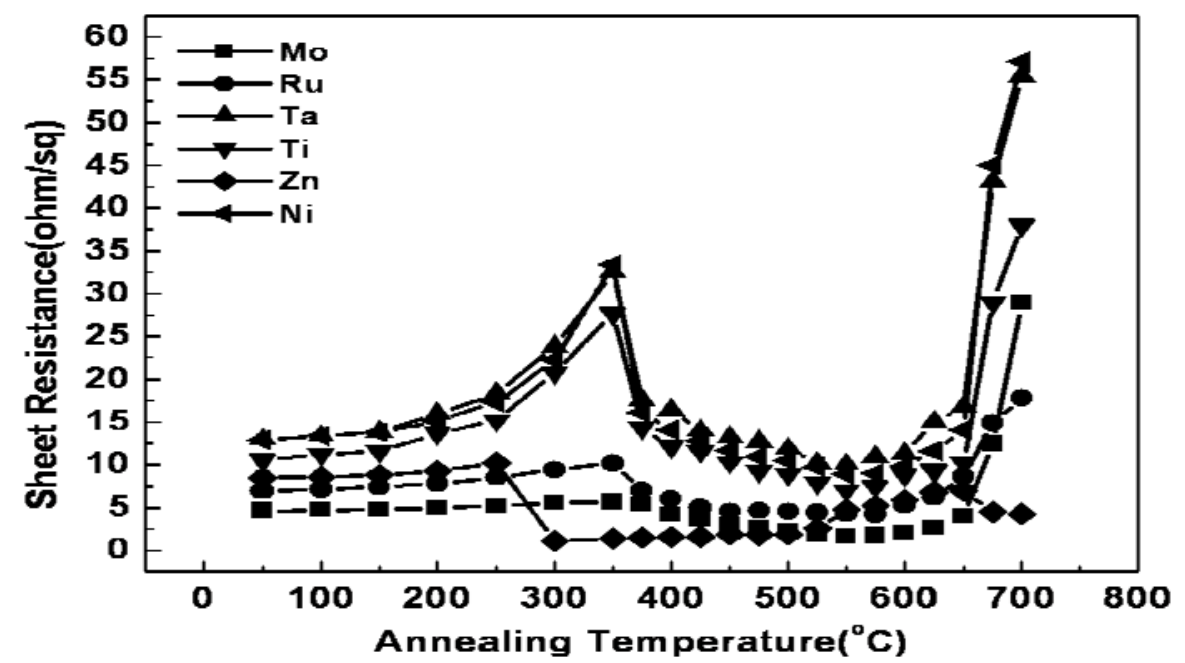

Fig. 2 In-Situ Rs of Ni silicides with different silicidation temperatures.

showed Rs of about 35 ohmic/sq at annealing temperatures from $300-400{ }^{\circ} \mathrm{C}$. When the Mo, Ru and $\mathrm{Zn}$ interlayers were added to the $\mathrm{Ni} / \mathrm{Si}$ system, there was a rapid drop in the Rs curve at higher temperatures (450-650 ${ }^{\circ} \mathrm{C}$ ). When the Mo, Ru and $\mathrm{Zn}$ interlayers were added to the $\mathrm{Ni} / \mathrm{Si}$ system, there was a sheet resistance of 3-10 ohmic/sq at annealing temperatures from $450-650{ }^{\circ} \mathrm{C}$. On the other hand, when the Ta and $\mathrm{Ti}$ interlayers were added to $\mathrm{Ni} / \mathrm{Si}$, there was a sheet resistance of 12-15 ohmic/sq at annealing temperatures from $450-650{ }^{\circ} \mathrm{C}$. This indicates that the Mo, Ru and $\mathrm{Zn}$ interlayers can improve the thermal stability of $\mathrm{Ni}$ silicides. Fig. 2 shows that the Zn-inserted nickel silicide had the lowest NiSi formation temperature of $300{ }^{\circ} \mathrm{C}$. Even that, the Rs of the Zn-inserted nickel silicide could sustain at $\sim 2.5 \mathrm{ohmic} / \mathrm{sq}$ at annealing temperatures from $300{ }^{\circ} \mathrm{C}$ to $600{ }^{\circ} \mathrm{C}$ and then slightly rise to $\sim 4.3 \mathrm{ohmic} / \mathrm{sq}$ when the annealing temperature was greater than $600{ }^{\circ} \mathrm{C}$. In this study, Zn performed the best $\mathrm{NiSi}$ thermal stability among all metal interlayers.

The GLXRD plots of the Ni films with the Mo, Ru, $\mathrm{Ta}, \mathrm{Ti}$ and $\mathrm{Zn}$ interlayers at $500{ }^{\circ} \mathrm{C}$ and $700{ }^{\circ} \mathrm{C}$ are shown in Figs. 3a and 3b, respectively. Fig. 3a shows that there were NiSi peaks at 2-theta of $30^{\circ}-60^{\circ}$ and no $\mathrm{NiSi}_{2}$ peaks in the Mo, $\mathrm{Ru}, \mathrm{Ta}, \mathrm{Ti}$ and $\mathrm{Zn}$ interlayer samples at annealing temperature of $500{ }^{\circ} \mathrm{C}$. Fig. 3b shows that the low-resistance phase "NiSi” still existed at $700{ }^{\circ} \mathrm{C}$ for all samples, but the high-resistance phases " $\mathrm{NiSi}_{2}$ (200)" were formed in the $\mathrm{Ta}$ and $\mathrm{Ti}$ interlayer Ni silicide. In the Ru interlayer Ni silicide, there was a $(\mathrm{NiRu}) \mathrm{Si}_{\mathrm{x}}$ alloy phase at 2 theta of $41^{\circ}$, but this still does not cause an increase in the Rs. In addition, the $\mathrm{Zn}$ interlayer nickel silicide which had the lowest Rs at 300-700 ${ }^{\circ} \mathrm{C}$ had higher $\mathrm{NiSi}(211)$ and $\mathrm{NiSi}(310)$ peaks at the annealing temperature of $500{ }^{\circ} \mathrm{C}$. The result may indicate that the $\mathrm{NiSi}(211)$ and $\mathrm{NiSi}(310)$ had lower resistance than other NiSi phases.

Fig. 4 shows the FESEM images of the surface condition of Mo, Ru, Ta, Ti and Zn inserted nickel silicide at a silicidation temperature of $500{ }^{\circ} \mathrm{C}$. The Mo, $\mathrm{Ru}$ and $\mathrm{Zn}$ interlayer nickel silicide shown in Figs. 4a, $4 \mathrm{~b}$ and $4 \mathrm{e}$ has a relatively smooth uniform surface at $600{ }^{\circ} \mathrm{C}$, while the $\mathrm{Ta}$ and $\mathrm{Ti}$ interlayer layer nickel silicide gradually has disordered surface grains, as shown in Figs. 4c and 4d. The disordered surface grains have an average width of 100-350 nm.

Fig. 5 shows the FESEM images of the surface condition of Mo, Ru, Ta, Ti and Zn inserted nickel silicide at silicidation temperature of $700{ }^{\circ} \mathrm{C}$. In contrast in Figs. 4a, 4b and 4e average grain width is 20-30 nm, in Figs. 5a, 5b and 5c the average grain width is $40-50 \mathrm{~nm}$. The disordered surface grains of Ta and Ti interlayer nickel silicide in in Figs. 5c and 5d, show more agglomeration than those in Figs. 4c and $4 d$. 

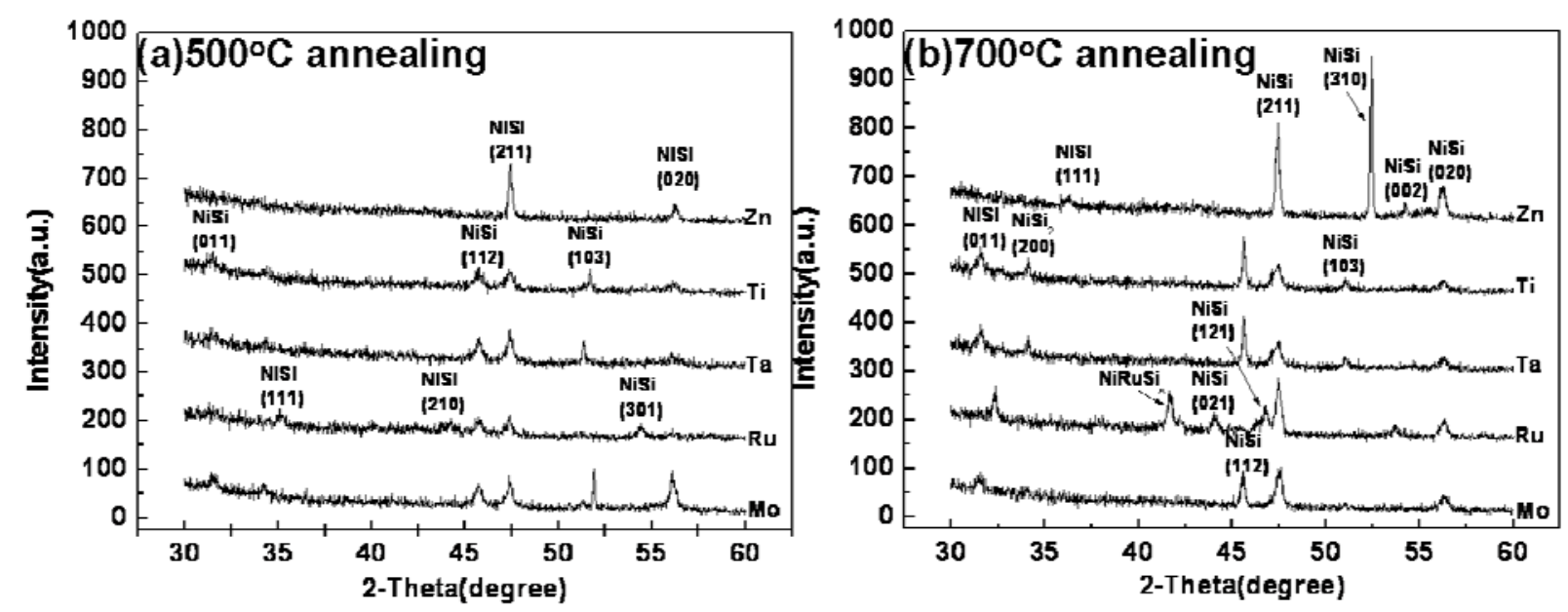

Fig. 3 GLXRD plots of the nickel silicide with different interlayers at the annealing temperature of: (a) $500{ }^{\circ} \mathrm{C}$ and (b)700 ${ }^{\circ} \mathrm{C}$.
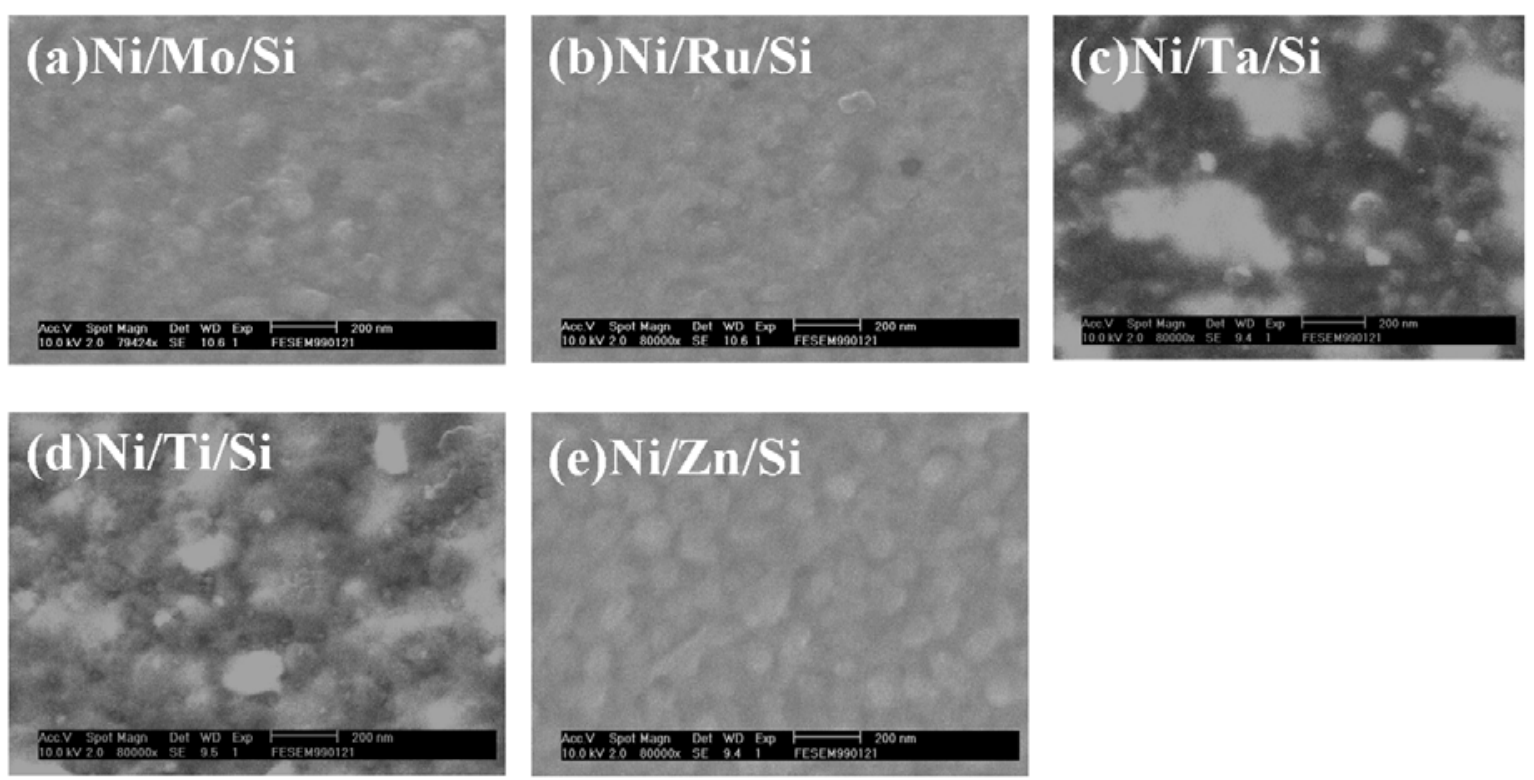

Fig. 4 Plan-view FESEM images of Ni silicides that were obtained from different interlayers (Mo, Ru, Ta, Ti and $\mathrm{Zn}$ ) and annealed at $600{ }^{\circ} \mathrm{C}$.

Fig. 6 shows the FESEM images of the surface condition of $\mathrm{Mo}, \mathrm{Ru}, \mathrm{Ta}, \mathrm{Ti}$ and $\mathrm{Zn}$ inserted nickel silicide at a silicidation temperature of $800{ }^{\circ} \mathrm{C}$. Figs. 6a and $6 \mathrm{~b}$ show evident surface roughness, but in Fig. 6c the $\mathrm{Zn}$ interlayer nickel silicide is still effective in inhibiting surface agglomeration. The disordered surface grains of Ta and $\mathrm{Ti}$ interlayer nickel silicide shown in Figs. 6c and 6d have a surface roughness higher than those in Figs. 4 and 5. These result show that the $\mathrm{Ta}$ and $\mathrm{Ti}$ interlayer nickel silicide inhibits surface agglomeration less and has worse thermal stability than $\mathrm{Mo}, \mathrm{Ru}$ and $\mathrm{Zn}$ interlayer nickel silicide. In contrast, the $\mathrm{Zn}$ interlayer nickel silicide inhibits the surface agglomeration more and has better thermal stability than the Mo and Ru interlayer nickel silicide.

Fig. 7 shows the TEM images of the cross-sectional of (a) Ni/interlayer before annealing, (b) Ni/Mo/Si, (c) $\mathrm{Ni} / \mathrm{Ru} / \mathrm{Si}$, (d) Ni/Ta/Si, (e) Ni/Ti/Si and (f) Ni/Zn/Si at $700{ }^{\circ} \mathrm{C}$. In Figs. 7b-7f, the nickel-silicide films were irregular with grooves at the silicide/Si interface. In Figs. $7 \mathrm{~b}$ and $7 \mathrm{f}$, the nickel-silicide films are still smooth. A signify the Mo and Zn metal inhibit surface 

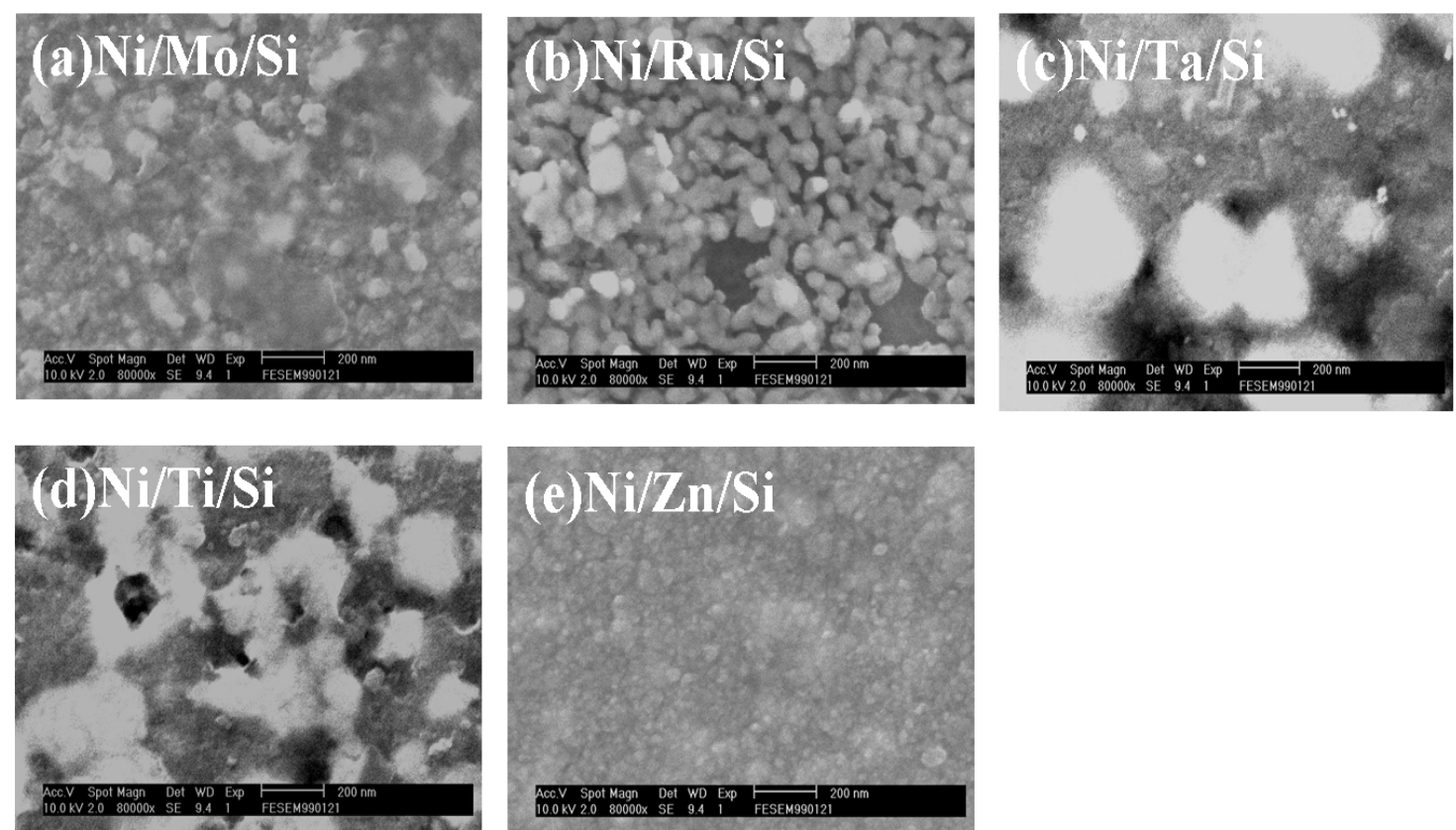

Fig. 6 Plan-view FESEM images of Ni silicides that were obtained from different interlayers (Mo, Ru, Ta, Ti and $\mathrm{Zn}$ ) and annealed at $800{ }^{\circ} \mathrm{C}$.
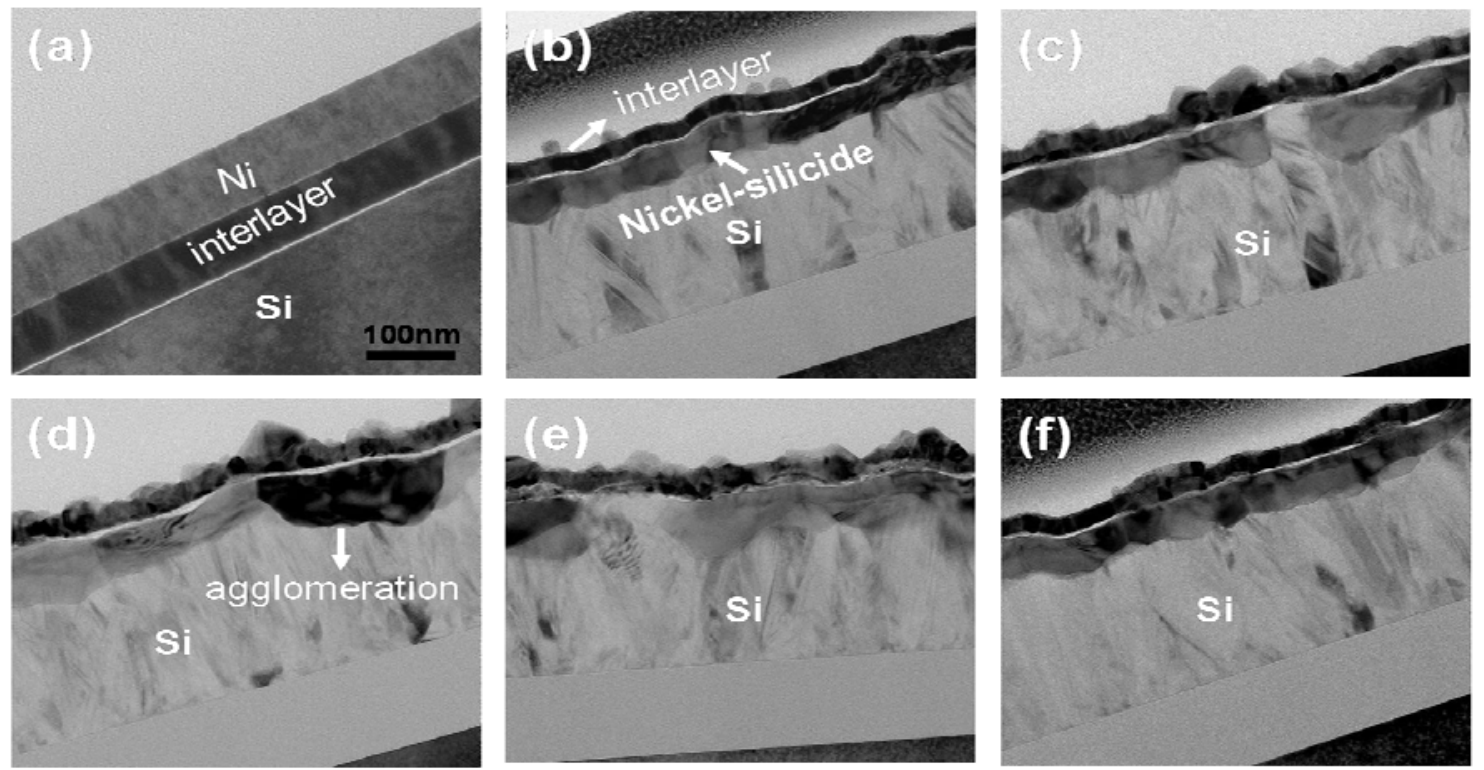

Fig. 7 TEM cross-sectional profiles of (a) Ni/interlayer before annealing, (b) Ni/Ti/Si $700{ }^{\circ} \mathrm{C}$, (c) Ni/Ru/Si $700{ }^{\circ} \mathrm{C}$, (d) $\mathrm{Ni} / \mathrm{Zn} / \mathrm{Si}$ $700{ }^{\circ} \mathrm{C}$, (e) Ni/Ti/Si $700{ }^{\circ} \mathrm{C}$ and (f) Ni/Zn/Si $700{ }^{\circ} \mathrm{C}$.

agglomeration behavior was better than $\mathrm{Ru}$, Ta and $\mathrm{Ti}$. Figs. 7c-7e exhibit Ru, Ta and Ti interlayer annealing at $700{ }^{\circ} \mathrm{C}$. The result found the nickel-silicide films was irregular with grooves and inhibits surface agglomeration less than Mo and $\mathrm{Zn}$ metal.

Fig. 8 shows the Tafel corrosion rate curves of NiSi and different metal interlayers (Mo, Ru, Ta, Ti and Zn) in the $\mathrm{H}_{2} \mathrm{SO}_{4}: \mathrm{H}_{2} \mathrm{O}_{2}=4: 1$ selectivity etching solution at $80{ }^{\circ} \mathrm{C}$. It was seen that the corrosion currents $\left(I_{\text {corr }}\right)$ of the $\mathrm{Mo}, \mathrm{Ru}, \mathrm{Ti}$ and $\mathrm{Zn}$ films were higher than that of NiSi while the $I_{\text {corr }}$ of the Ta film was lower than that of NiSi.

Table 1 also shows that the etching rates of the NiSi and different metal interlayers in the $\mathrm{H}_{2} \mathrm{SO}_{4}: \mathrm{H}_{2} \mathrm{O}_{2}=4: 1$ 


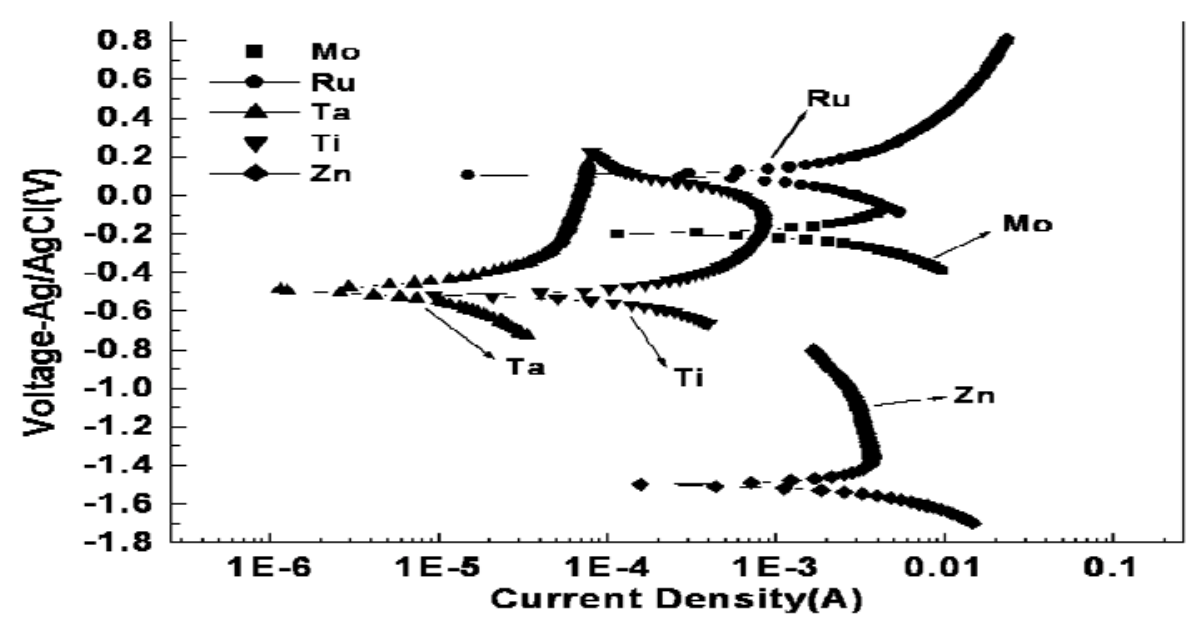

Fig. 8 Potential dynamic curves of the different interlayer (Mo, Ru, Ta, Ti and Zn) in $\mathrm{H}_{2} \mathrm{SO}_{4}: \mathrm{H}_{2} \mathrm{O}_{2}=4: 1$ selectivity etching solution at $80^{\circ} \mathrm{C}$.

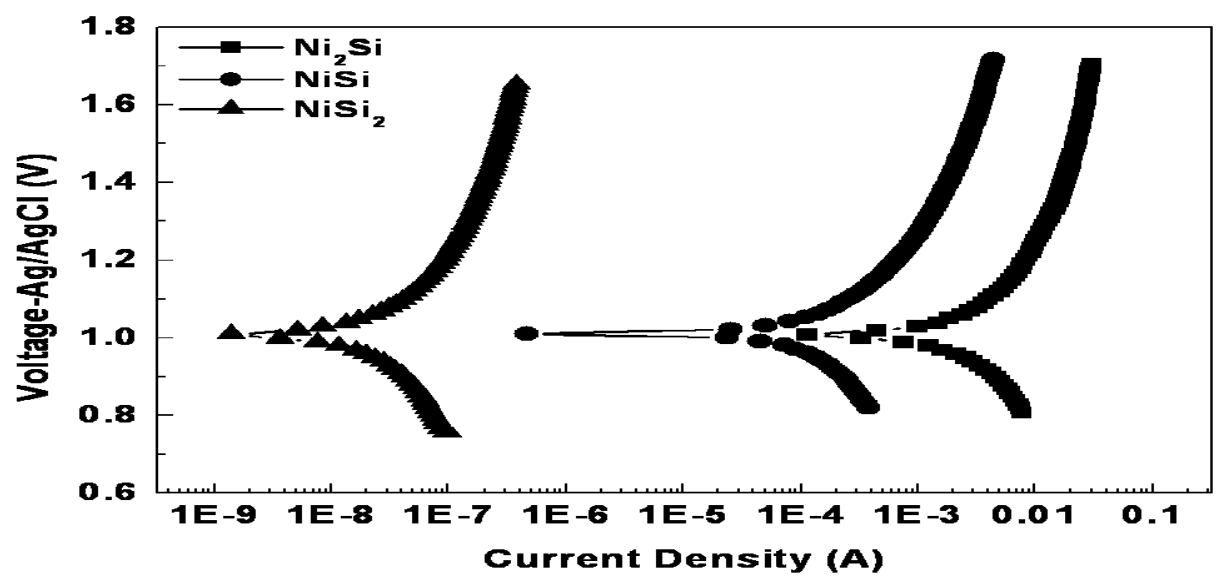

Fig. 9 Potential dynamic curves of the $\mathrm{Ni}_{2} \mathrm{Si}$, NiSi and $\mathrm{NiSi}_{2}$ in $\mathrm{H}_{2} \mathrm{SO}_{4}: \mathrm{H}_{2} \mathrm{O}_{2}=4: 1$ selectivity etching solution at $80{ }^{\circ} \mathrm{C}$.

Table $1 I_{c o r r}$ and etching rates of $\mathrm{NiSi}$ and different metal interlayers in the $\mathrm{H}_{2} \mathrm{SO}_{4}: \mathrm{H}_{2} \mathrm{O}_{2}=4: 1$ solution at $80{ }^{\circ} \mathrm{C}$.

\begin{tabular}{lcccccc}
\hline \multicolumn{1}{c}{ Interlayer } & Mo & Ru & Ta & Ti & Zn & NiSi \\
\hline \multicolumn{1}{c}{ Icroo (A) } & $2.79 \times 10^{-2}$ & $6.31 \times 10^{-2}$ & $\mathbf{8 . 1 4 \times 1 0 ^ { - 4 }}$ & $\mathbf{8 . 8 7 \times 1 0 ^ { - 3 }}$ & $2.54 \times 10^{-2}$ & $3.97 \times 10^{-3}$ \\
\hline $\begin{array}{l}\text { Remove Rate } \\
(\text { nm/min) }\end{array}$ & 2.5 & 1.3 & 0.72 & 0.85 & 3.3 & 0.81 \\
\hline
\end{tabular}

solution. The data also proved that the etching rates of $\mathrm{Mo}, \mathrm{Ru}, \mathrm{Ti}$ and $\mathrm{Zn}$ were higher than that of NiSi. In self-aligned silicidation process, the metal interlayers should have higher etching rate than that of $\mathrm{NiSi}$ in the selective etching solution to remain $\mathrm{NiSi}$.

Fig. 9 shows the Tafel corrosion rate curves of the different nickel-silicide phases $\left(\mathrm{Ni}_{2} \mathrm{Si}\right.$, $\mathrm{NiSi}$ and $\left.\mathrm{NiSi}_{2}\right)$ in the $\mathrm{H}_{2} \mathrm{SO}_{4}: \mathrm{H}_{2} \mathrm{O}_{2}=4: 1$ selectivity etching solution at $80^{\circ} \mathrm{C}$. It is seen that the corrosion currents $\left(I_{\text {corr }}\right)$ of the $\mathrm{Ni}_{2} \mathrm{Si}$ films are much higher than those of the NiSi and
$\mathrm{NiSi}_{2}$ films. However, the $\mathrm{Ni}_{2} \mathrm{Si}-\mathrm{Rs}$ were higher than $\mathrm{NiSi}$-Rs and the NiSi-Rs were lower than $\mathrm{NiSi}_{2}$-Rs. In this work, the corrosion rate of the metal must higher than nickel silicide (NiSi phase). It is found that the corrosion current $\left(I_{\text {corr }}\right)$ of the NiSi films are lower than that of the Mo, $\mathrm{Ru}$ and $\mathrm{Zn}$ films in $\mathrm{H}_{2} \mathrm{SO}_{4}: \mathrm{H}_{2} \mathrm{O}_{2}=4: 1$ selectivity etching solution at $80^{\circ} \mathrm{C}$.

Table 1 shows the metal etching rate in $\mathrm{H}_{2} \mathrm{SO}_{4}: \mathrm{H}_{2} \mathrm{O}_{2}$ $=4: 1$ at $80{ }^{\circ} \mathrm{C}$ and $\mathrm{Rs}$ at $700{ }^{\circ} \mathrm{C}$ of the different metal interlayers (Mo, $\mathrm{Ru}, \mathrm{Ta}, \mathrm{Ti}$ and $\mathrm{Zn}$ ). The results prove 
that the removal rates of the Mo and $\mathrm{Zn}$ films are much fast than those of the $\mathrm{Ru}$, $\mathrm{Ta}$ and $\mathrm{Ti}$ films in $\mathrm{H}_{2} \mathrm{SO}_{4}: \mathrm{H}_{2} \mathrm{O}_{2}=4: 1$ at $80{ }^{\circ} \mathrm{C}$ that the corrosion current ( $\mathrm{I}_{\text {corr }}$ ) of the Mo and $\mathrm{Zn}$ films are lower than those of the $\mathrm{Ru}, \mathrm{Ta}$ and $\mathrm{Ti}$ films at $700{ }^{\circ} \mathrm{C}$.

\section{Conclusions}

In this study, the effects of different interlayers (Mo, $\mathrm{Ru}, \mathrm{Ta}, \mathrm{Ti}$ and $\mathrm{Zn}$ ) in-situ Rs on the thermal stability and structural properties of nickel silicide films were investigated. Both without and with an interlayer, the sheet resistance (Rs) increased with increasing annealing temperature, and the interlayers (Mo, Ru, Ta, $\mathrm{Ti}$ and $\mathrm{Zn}$ ) showed better characteristics. The results prove that the Rs of the $\mathrm{Ru}$ and $\mathrm{Zn}$ films are low than those of the Mo, Ta and Ti films at $700{ }^{\circ} \mathrm{C}$. The GLXRD results show that the $\mathrm{Zn}$ interlayer nickel silicide has the lowest sheet resistance of the in-situ Rs at 300-600 ${ }^{\circ} \mathrm{C}$. The FESEM images show that the $\mathrm{Zn}$ interlayer nickel silicide inhibits both surface agglomeration and thermal stability more than the Mo and $\mathrm{Ru}$ interlayer nickel silicide. Both $\mathrm{Ta}$ and $\mathrm{Ti}$ interlayers were not effective in inhibiting surface agglomeration and thermal stability. Because the nickel film which had a diffusion behavior is better than interlayer (Mo, Ru, Ta, Ti or $\mathrm{Zn}$ ), which choose inhibit diffusion behavior was bad of metal for silicidation. The Tafel corrosion rate shows that the intrinsic corrosion rate of the Mo and Zn films is much higher than that of the $\mathrm{Ru}$, Ta and Ti films, and the metal etching rate of the Mo and $\mathrm{Zn}$ films is much faster than that of $\mathrm{Ru}$, Ta and Ti films in $\mathrm{H}_{2} \mathrm{SO}_{4}: \mathrm{H}_{2} \mathrm{O}_{2}=$ $4: 1$ at $80^{\circ} \mathrm{C}$. It is found that the corrosion current $\left(I_{\text {corr }}\right)$ of the NiSi films are lower than that of the Mo, Ru and $\mathrm{Zn}$ films in $\mathrm{H}_{2} \mathrm{SO}_{4}: \mathrm{H}_{2} \mathrm{O}_{2}=4: 1$ selectivity etching solution at $80^{\circ} \mathrm{C}$. The Ta and Ti interlayer had the best inhibit diffusion behavior, which corrosion rate was lower than $\mathrm{Mo}, \mathrm{Ru}, \mathrm{Zn}$, and NiSi phase.

\section{References}

[1] Maex, K. 1993. Mater. Sci. Eng. R. 11: 53.

[2] Beyers, R., and Sinclair, R. 1985. J. Appl. Phys. 57: 5240.

[3] Ma, Z., and Allen, L. H. 1994. Phys. Rev. B 49: 13501.

[4] Lee, P. S., Pey, K. L., Mangelinck, D., Ding, J., Chi, D. Z., and Chan, L. 2001. IEEE Electron Device Lett. 22: 568.

[5] Saha, S. K., Howell, R. S., and Hatalis, M. K. 1999. Thin Solid Films 347: 278.

[6] Zhang, S. K., and Ostling, M. 2003. Crit. Rev. Solid State Mater. Sci. 28: 1.

[7] Morimoto, T., Momose, H. S., Iinuma, T., Kunishima, I., Suguro, K., Okano, H., and et al. 1991. IEDM Tech. Dig. 653.

[8] Morimoto, T., Ohguro, T., Momose, H. S., Iinuma, T., Kunishima, I., Sugruo, K., and et al. 1995. IEEE Trans. Electron Devices 42 (5): 915-922.

[9] Lavoie, C., d’Heurle, F. M., Detavernier, C., Cabral Jr., C. 2003. Microelectron. Eng. 70: 144.

[10] Xu, D. X., Das, S. R., Peters, C. J., and Erickson, L. E. 1998. Thin Solid Films 326: 143.

[11] Tan, W. L., Pey, K. L., Chooi, S. Y. M., Ye, J. H., and Osipowicz, T. 2002. J. Appl. Phys. 91: 2901.

[12] Huang, W., Zhang, L., Gao, Y., and Jin, H. 2006. Microelectron. Eng. 83: 345.

[13] Yoon, K. I., Song, O. S. 2006. Kor. J. Mater. Res. 16: 9. 